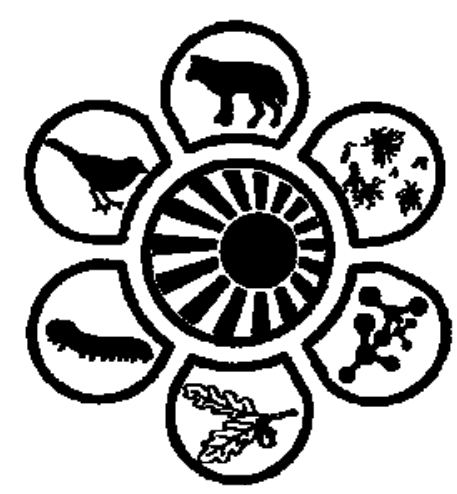

Вісник Дніпропетровського університету. Біологія, екологія.

Vìsnik Dnìpropetrovs'kogo unìversitetu. Seriâ Bìologiâ, ekologiâ

Visnyk of Dnipropetrovsk University. Biology, ecology.

Vìsn. Dnìpropetr. Unìv. Ser. Bìol. Ekol. 2016. 24(1), 193-202.

doi: $10.15421 / 011624$

ISSN 2310-0842 print

ISSN 2312-301X online

www.ecology.dp.ua

УДК 597.851(576.354.4)

Устойчивость сперматогенеза и проявления отбора на клеточном и индивидуальном уровнях у незрелых представителей Pelophylax esculentus complex

\author{
О.В. Бирюк, Е.Е. Усова, Е.В. Мелешко, Д.А. Шабанов \\ Харьковский наџиональный университет имени В.Н. Каразина, Харьков, Украина
}

Исследована случайная выборка неполовозрелых зеленых лягушек из Северско-Донецкого центра разнообразия Pelophylax esculentus complex. У каждой особи определяли пол, возраст (методом скелетохронологии), плоидность и принадлежность к P. esculentus или P. ridibundus, а также измеряли длину тела и длину семенников у самцов. По мазкам крови определяли среднюю длину эритроцитов. Из семенников изготавливали кариологические препараты, по которым описывали кариотипы клеток во время митотических и мейотических делений. Проведен метаанализ результатов данной и предшествовавших работ, в которых определяли состав выборок зеленых лягушек пойме р. Северский Донец в окрестностях Биологической станции Харьковского национального университета имени В.Н. Каразина. Доля триплоидных P. esculentus ниже всего у метаморфов, повышается (вследствие гибели представителей родительского вида, появляющихся от скрещивания гибридов) у незрелых особей и снижается (из-за большей смертности триплоидов) у половозрелых особей. Диплоидные лягушки имеют длину эритроцитов менее 28 мкм, триплоидные - более 27 мкм; в диапазоне 27-28 мкм по длине эритроцитов установить плоидность невозможно. Незрелые $P$. esculentus имеют тенденцию к задержке развития гонад и значимо большее количество аномальных кариотипов в митозе и мейозе, чем P. ridibundus. Повышение устойчивости сперматогенеза у половозрелых лягушек по сравнению с незрелыми может быть следствием как отбора клеточных линий внутри семенников, так и преимущественного выживания особей с относительно более устойчивым гаметогенезом.

Ключевые слова: гемиклональные популяционные системы; триплоиды; сперматоциты I; биваленты

\title{
Stability of spermatogenesis \\ and displays of natural selection at the cellular and individual level in immature representatives of the Pelophylax esculentus complex
}

\author{
O. Biriuk, O. Usova, O. Meleshko, D. Shabanov \\ V.N. Karazin Kharkiv National University, Kharkiv, Ukraine
}

Pelophylax esculentus is an interspecific hybrid which reproduces hemiclonally by crossing with the parental species $(P$. ridibundus or $P$. lessonae). The structure of hemiclonal population systems is of great interest. The majority of investigations into populations of water frogs deal with samples of mature animals, while subadults are less studied. We collected a random sample of 73 small water frogs from three localities in the Siverskyi Donets River floodplain. All frogs were measured, injected with colchicines and killed after anesthesia. We determined the species specifity, sex, age and ploidy of every individual. In addition, we measured testis length and studied the germ cells of all males by means of karyological analysis. We calculated the portion of triploids in the largest subsample from the vicinity of the Biological Station of V.N. Karazin Kharkiv National University and carried out a meta-analysis of previous publications dealing with composition of green frog samples from this locality. The proportion of triploids in our sample appeared to be approximately the same as 12 years ago. However, this proportion in our sample differed significantly from that obtained in recent samples of green frogs belonging to other age groups (adults and metamorphs) from the same locality. The share of triploids of $P$. esculentus is the lowest in the sample of metamorphs. This proportion increases in froglets because of early death of representatives of parental species which originated from hybrid-

Харьковский национальный университет имени В. Н. Каразина, пл. Свободы, 4, Харьков, 61022, Украина

V.N. Karazin Kharkiv National University, Svobody Sq., 4, Kharkiv, 61022, Ukraine

Tel.:+38-057-705-12-48.E-mail:d.a.shabanov@gmail.com,mykhailova.o.v@gmail.com

Visn. Dnipropetr. Univ. Ser. Biol. Ekol. 2016. 24(1) 
hybrid crossing. Then the number of triploids among adult $P$. esculentus individuals declines again probably because of their lower viability compared to diploids. We have revealed that subadult diploids have erythrocytes smaller than 28 microns, while triploids' erythrocytes exceed 27 microns. Therefore, in borderline cases true ploidy could be determined only by the karyological technique. The average ratio between testis length and body length appeared to be larger in the parental species than in both diploid and triploid hybrids. Karyological analysis has revealed that $P$. esculentus had significantly lower portions of spermatocytes I with normal karyotype (13 bivalents) in the testis in comparison with $P$. ridibundus, but this value increases in adult hybrids. We suggest that increasing of spermatogenesis stability in adult frogs as opposed to subadults might be the consequence of both selection of germ cell lines in the testis and more frequent survival of individuals with stable gametogenesis.

Keywords: hemiclonal population systems; triploids; spermatocytes I; bivalents

\section{Введение}

Два широко распространенных в Украине и Европе в целом вида, Pelophylax ridibundus (Pallas, 1771) и P. lessonae (Camerano, 1882), а также их межвидовой гибрид $P$. esculentus (Linnaeus, 1758) составляют гибридогенную группу зеленых лягушек, P. esculentus complex. Гибридное происхождение и особый полуклональный способ воспроизводства P. esculentus открыты во второй половине XX века (Berger, 1964; Tunner, 1974). Полуклональный или гемиклональный тип наследования предполагает полное удаление одного из родительских геномов из клеток зародышевой линии и дальнейшую передачу в гаметы генома другого родительского вида в чистоте (Bulger and Schultz, 1982). У P. esculentus удаление неклонального генома происходит во время митотических делений клеток зародышевой линии, после чего оставшийся (клональный) геном удваивается до вступления клеток в мейоз (Tunner and Heppich-Tunner, 1991). У триплоидных особей в случае, который можно считать типичным, гаметогенез протекает аналогично, за исключением стадии удвоения (Vinogradov et al., 1991). Описанные необычные особенности гаметогенеза обеспечивают воспроизводство межвидовых гибридов в условиях совместного обитания и размножения различных представителей $P$. esculentus complex. Системы, в которых происходит воспроизводство P. esculentus, названы гемиклональными популяционными системами, ГПС (Shabanov and Litvinchuk, 2010). В ГПС разного состава устойчивое воспроизводство $P$. esculentus оказывается возможным благодаря разному характеру их гаметогенеза (Shabanov et al., in press). Например, в регионе, названном Северско-Донецким центром разнообразия $P$. esculentus complex, и среди самцов, и среди самок зарегистрированы диплоидные $P$. esculentus, передающие в гаметах геномы $P$. ridibundus, $P$. lessonae, те и другие одновременно, а также производящие анеуплоидные гаметы или гаметы, несущие смесь хромосом родительских видов (Dedukh et al., 2013, 2015; Biriuk et al., in press). Таким образом, необычный характер гаметогенеза P. esculentus и его разнообразие являются приспособлением к их способу воспроизводства в составе ГПС.

Одним из следствий аномального гаметогенеза гибридных лягушек является то, что их воспроизводство сталкивается с рядом трудностей. К их числу относятся задержка и нарушения развития гонад (Ogielska, 1995; Ogielska and Bartmanska, 1999), аномалии личиночного развития и снижение жизнеспособности гибридов (Tunner, 1979; Berger, 2008; Ogielska, 2009), а также нарушения мейоза, приводящие к полной или частичной стерильности (Günther, 1973; Uzzell et al., 1977; Berger and Günther, 1988).
Значительная доля самцов P. esculentus из СеверскоДонецкого центра разнообразия зеленых лягушек также демонстрирует пониженную фертильность (Bobrova et al., 2014; Biriuk et al., in press). С помощью кариологического анализа метафазных пластинок сперматоцитов I у половозрелых гибридов установлено, что доля клеток, несущих нормальные хромосомные наборы (13 бивалентов), у гибридов составляет в среднем $51 \%$, в то время как у родительского вида $P$. ridibundus - 86\% (Vegerina et al., 2014). Большая часть публикаций, посвященных проблеме гаметогенеза $P$. esculentus в ГПС различного состава, базируется на изучении выборок половозрелых особей и анализе потомства от их скрещиваний (Christiansen, 2009; Christiansen and Reyer, 2009; Pruvost et al., 2013, Ragghianti et al., 2007). Данных о составе выборок неполовозрелых особей, а также об особенностях кариотипов их клеток зародышевой линии, явно недостаточно. Большинство исследований, посвященных изучению кариотипов клеток зародышевой линии зеленых лягушек, носит качественный характер, то есть регистрируют различные кариотипы без их точного подсчета (Günther, 1975; Suryadna, 2005; Manilo et al., 2007; Manilo et al., 2010). Количественная оценка аномалий гаметогенеза дает возможность сравнивать устойчивость гаметогенеза у различных зеленых лягушек.

Задача данной работы - определить состав выборки незрелых лягушек из Северско-Донецкого центра разнообразия $P$. esculentus complex, сравнить с ранее исследованными выборками, а также оценить распространенность различных аномалий в семенниках незрелых зеленых лягушек (межвидовых гибридов и представителей родительского вида).

\section{Материал и методы исследований}

Случайная выборка мелких неполовозрелых лягушек составила 73 особи. Все лягушки отловлены в конце сентября 2014 года в Харьковской области. Лягушек собирали в пойме реки Северский Донец в окрестностях с. Гайдары Змиевского района и в п. Эсхар Чугуевского района, а также в пойме реки Лопань в г. Дергачи Дергачевского района (табл. 1). Следует отметить, что мелкие экземпляры в этот период часто собираются на мелководьях, в то время как половозрелые особи в таких участках очень редки. Длина тела изученных особей находилась в пределах от 20,7 до 45,3 мм.

В состав изучаемой выборки вошли незрелые лягушки. Следует подчеркнуть, что у некоторых из них в семенниках были обнаружены сперматиды и зрелые спермии, что дает основание считать их половозрелыми. Однако у зеленых лягушек полноценное участие в нересте может начинаться позже приобретения особью 
способности к производству половых продуктов (Usova et al., 2015). Незрелость изученных нами особей означает то, что они не достигли размеров, характерных для особей, принимающих участие в нересте, а также не имеют отчетливо выраженных вторичных половых признаков (как резонаторы и брачные мозоли у самцов).

\section{Состав изученного в работе материала}

Таблица 1

\begin{tabular}{|c|c|c|c|c|c|}
\hline \multicolumn{2}{|c|}{$\begin{array}{c}\text { Представители } \\
\text { Pelophylax esculentus } \\
\text { complex }\end{array}$} & с. Гайдары & г. Эсхар & г. Дергачи & Всего \\
\hline \multirow{3}{*}{ P. ridibundus } & самцы & 11 & - & 2 & 13 \\
\hline & самки & 20 & 1 & 3 & 24 \\
\hline & всего & 31 & 1 & 5 & 37 \\
\hline \multirow{3}{*}{$\begin{array}{c}\text { P. esculentus, } \\
2 \mathrm{n}\end{array}$} & самцы & 20 & - & - & 20 \\
\hline & \begin{tabular}{|l|} 
самки \\
\end{tabular} & 5 & - & - & 5 \\
\hline & всего & 25 & - & - & 25 \\
\hline \multirow{3}{*}{$\begin{array}{l}\text { P. esculentus, } \\
\text { 3n }\end{array}$} & самцы & 5 & 1 & - & 6 \\
\hline & самки & 2 & 3 & - & 5 \\
\hline & всего & 7 & 4 & - & 11 \\
\hline \multicolumn{2}{|l|}{ Всего } & 63 & 5 & 5 & 73 \\
\hline
\end{tabular}

Видовую принадлежность особей определяли по комплексу внешних признаков (Shabanov et al., 2006). Животных колхицинировали, через 24 часа после инъекции усыпляли с помощью этилацетата и вскрывали под бинокулярной лупой. По морфологии гонад определяли пол особи. Семенники вырезали, измеряли и фиксировали в фиксаторе Карнуа после предварительного выдерживания в гипотоническом растворе. Те же манипуляции, кроме измерения, проделывали с фрагментом кишечника. Кроме того, для каждой особи изготавливали мазок крови.

Возраст лягушек определен методом скелетохронологии на основании анализа срезов фаланги четвертого пальца задней ноги каждой особи (Smirina, 1983; Usova, 2010).

Определение плоидности проводили на основании согласованных результатов двух методов: анализа рас- капанных кариологических препаратов эндотелия кишечника (Vegerina et al., 2014) и измерения размеров эритроцитов на мазках крови (Bondarieva et al., 2012). Количество хромосом подсчитывали как минимум в пяти полных метафазных пластинках, если же на препарате не было достаточного числа качественных метафаз, плоидность определяли по количеству ЯОР в интерфазных ядрах (Vegerina et al., 2013).

Кариологические препараты семенников изготавливали и окрашивали по методике, аналогичной той, которую использовали для соматических тканей (Vegerina et al., 2014). На препаратах находили и фотографировали все мейотические и митотические пластинки, в которых можно было посчитать количество структур (хромосом, бивалентов или унивалентов). Затем по фотографиям, с помощью графического редактора Adobe Photoshop, производили подсчет структур каждого типа в каждой пластинке. Сперматогониальные деления (митоз) и сперматоциты I порядка (мейоз) учитывались отдельно. При этом для первых нормой считали 26 хромосом в случае диплоидов и 39 или 26 - в случае триплоидов. Сперматоциты I относили к нормальным, если в пластинке присутствовали 26 хромосом, образующие 13 бивалентов. Если же в мейотической пластинке удавалось обнаружить число хромосом, соответствующее диплоидному набору, но хромосомы не объединялись в биваленты, такая пластинка также считалась отклонением от нормы.

\section{Результаты и их обсуждение}

Состав выборки и доля триплоидных гибридов. Одна из собранных нами выборок получена из локалитета, имеющего длительную историю изучения: поймы Северского Донца в окрестностях с. Гайдары, рядом с Биологической станцией Харьковского национального университета имени В.Н. Каразина (табл. 2).

Таблииа 2

Сравнение выборок зеленых лягушек, собранных в пойме р. Северский Донец рядом с Биологической станцией ХНУ имени В.Н. Каразина

\begin{tabular}{|c|c|c|c|c|c|c|}
\hline \multirow[b]{2}{*}{ Год сбора } & \multicolumn{2}{|c|}{ Состав выборки } & \multirow{2}{*}{$\begin{array}{l}\text { Количество } \\
\text { триплоидов }\end{array}$} & \multirow{2}{*}{$\begin{array}{l}\text { Доля триплоидов } \\
\text { от P. esculentus, \% }\end{array}$} & \multirow{2}{*}{$\begin{array}{c}\text { Доля триплоидов от } \\
\text { суммы P. esculentus } \\
\text { и P. ridibundus, \% }\end{array}$} & \multirow[b]{2}{*}{ Источник } \\
\hline & P. esculentus & P. ridibundus & & & & \\
\hline $2002-2004$ & 14 juv & 11 juv & 3 juv & 21,0 & 12,0 & Borkin et al., 2004 \\
\hline 2008 & $\begin{array}{c}94 \hat{\sigma^{\wedge}}, 1 \text { क, } \\
1 \text { неопр. }\end{array}$ & $51 \widehat{\partial} \widehat{\partial}$ & $\begin{array}{l}12 \hat{\jmath} \widehat{\gamma}, \\
1 \text { неопр. }\end{array}$ & 13,5 & 8,8 & $\begin{array}{l}\text { Mezhzherin } \\
\text { et al., } 2010\end{array}$ \\
\hline 2012 & $67 \hat{\jmath} \hat{0}$ и $\phi$ 우 & - & 7 & 10,5 & - & Kozak et al., 2012 \\
\hline 2013 & \multicolumn{2}{|c|}{30 met } & - & - & $0(?>0)$ & Vegerina et al., 2013 \\
\hline 2014 & 32 juv & 31 juv & 7 & 22,0 & 11,0 & наши данные \\
\hline Всего juv & $14+32=46$ & $11+31=42$ & $3+10=10$ & 21,7 & 11,7 & объединенные \\
\hline Всего ठิธ и и 우우 & $95+67=162$ & - & $12+7=19$ & 11,7 & - & результаты \\
\hline
\end{tabular}

Примечание: $\hat{\jmath} \hat{\jmath}$ - половозрелые самцы; $q$ - половозрелые самки; јuv - незрелые особи обоих полов возрастом более одного года; met - метаморфы (особи сразу после метаморфоза).

В работе, где впервые сообщалось об обнаружении триплоидных гибридов в бассейне Северского Донца (Borkin et al., 2004), выборка из этого локалитета имела условное название «Biostantsiya». Состав изученной нами выборки вполне соответствует выборке, собранной на 1012 лет раньше, и резко отличается от выборки, собранной на 1-2 года ранее. В работе, где были опубликованы ре- зультаты обработки выборки, собранной в 2008 г. (Mezhzherin et al., 2010), высказано предположение о сокращении доли триплоидов в пойме р. Северский Донец в окрестностях с. Гайдары в течение прошедшего десятилетия. Чтобы проверить обоснованность этого предположения, в таблице 2 мы сгруппировали данные отдельно по незрелым и зрелым особям. Как легко убедиться, отличия 
в доле триплоидов, зарегистрированные в разных исследованиях, оказываются существенными в случае, если относятся к разным этапам онтогенеза. Результаты двух исследований, относящихся к зрелым особям, хорошо согласуются друг с другом, как и результаты двух исследований, рассматривавших состав незрелых особей. В единственной работе, посвященной метаморфам, триплоидов не оказалось; этот результат не позволяет оценить их долю, но показывает, что она является весьма невысокой.

На этом основании мы предполагаем, что различия в доле триплоидов, зарегистрированной в разных работах, отражают ее динамику в ходе онтогенеза зеленых лягушек. Тем не менее, имеющиеся данные позволяют провести метаанализ имеющихся данных и сформулировать гипотезу, описывающую динамику доли триплоидов в ГПС окрестностей Биостанции.

По критерию $\chi^{2}$ Пирсона зарегистрировано значимое $(\mathrm{P}<0,001)$ повышение доли триплоидов среди всех зеленых лягушек у неполовозрелых особей относительно той же доли у метаморфов. По тому же критерию регистрируется значимое $(\mathrm{P}<0,001)$ снижение доли триплоидов среди P. esculentus у половозрелых лягушек относительно неполовозрелых особей. Мы предполагаем, что низкая доля триплоидов среди метаморфов, высокая - среди неполовозрелых особей и сниженная - среди половозрелых лягушек отражает различный характер смертности диплоидных и триплоидных лягушек на разных этапах онтогенеза. Причины этого, по нашему мнению, таковы. При скрещивании между особями $P$. esculentus возникает значительное количество представителей родительских видов, получивших от разных родителей два клональных генома одного и того же вида. При скрещивании между особями P. esculentus возникает значительное количество представителей родительских видов, получивших от разных родителей два клональных генома одного и того же вида. В результате изменений геномов родительских видов при их клональной передаче такие особи оказываются нежизнеспособными и на ранних этапах развития (Guex et al., 2002). Кроме того при скрещивании $P$. esculentus, передающих в гаметы геном P. ridibundus, с представителями этого родительского вида возникают потомки того же вида. Это явление названо гибридолизом, буквально - «растворение гибридов», так как должно приводить к сокращению численности гибридов в популяции (Günther and Plötner, 1988). Особи, полученные в результате гибридолиза, часто также имеют нарушения развития и в большинстве случаев гибнут еще до достижения половозрелости (Berger, 1970, 1971; Tunner, 1979). Этот процесс приводит к сокращению доли диплоидных зеленых лягушек и, соответственно, к повышению доли триплоидных гибридов.

По нашей гипотезе, наблюдаемая динамика доли триплоидных гибридов в ГПС поймы р. Северский Донец в окрестностях Биостанции ХНУ имени В.Н. Каразина является результатом двух процессов: гибели вскоре после метаморфоза представителей родительских видов, являющихся результатом гибридолиза, а также повышенной смертности триплоидных гибридов в первые годы после метаморфоза. Проверка этой гипотезы требует дополнительного сбора и исследования выборок лягушек разных возрастных групп.

Размеры эритроцитов. Как и ожидалось, эритроциты триплоидных особей оказались гораздо крупнее, чем эритроциты диплоидов. Путем сопоставления результатов кариоанализа с измерениями эритроцитов мы определили, что граница между диплоидными и триплоидными эритроцитами лежит на уровне 28 мкм, хотя зарегистрировано даже незначительное перекрывание размеров диплоидных и триплоидных эритроцитов (рис. 1).

Это означает, что в тех случаях, когда длина эритроцитов приближается к 28 мкм, определение плоидности невозможно без кариологического анализа. В ранее проведенных исследованиях размеров эритроцитов половозрелых $P$. esculentus из бассейна р. Северский Донец граница между размерами триплоидных и диплоидных эритроцитов также установлена на отметке 28 мкм (Bondarieva et al., 2012). Однако считалось, что в разных размерных классах лягушек эта граница может смещаться, так как существует зависимость длины эритроцитов от длины тела (Plotner, 2005). Мы также обнаружили значимую положительную корреляцию между длиной эритроцитов и длиной тела лягушек (как у триплоидов, так и у диплоидов). Коэффициент корреляции Спирмана составил $0,72(\mathrm{P}=0,013)$ для диплоидных гибридов и P. ridibundus, а для триплоидных $-0,30(\mathrm{P}=0,018)$.

Размеры семенников и длина тела. Средняя относительная длина семенников у диплоидных и триплоидных P. esculentus оказалась значимо меньше, чем у P. ridibundus ( $\mathrm{U}=89,0, \mathrm{P}=0,016$ при сравнении по Манну-Уитни). Это свидетельство тенденции задержки развития или редукции гонад у гибридов (рис. 2). Возраст лягушек в изученной выборке составлял 1-5 лет. Большинство лягушек в выборке были двух- (52\%) и трехлетками (22\%). Мы сравнили среднюю длину тела двухлетних и трехлетних лягушек и выявили, что триплоиды растут быстрее, чем диплоиды. Однако отличия оказались незначимыми. Редкие зрелые спермии обнаружены в семенниках диплоидных $P$. esculentus, которые достигли возраста 4 и 5 лет. Однако среди триплоидов $P$. esculentus и $P$. ridibundus были самцы, которые производили небольшое количество зрелых спермиев уже в возрасте двух лет. Этот факт также указывает на задержку развития гонад у диплоидных гибридов.

Устойчивость сперматогенеза. Кариологический анализ выявил значимое снижение доли нормальных делений в семенниках гибридов по сравнению с представителями родительского вида $(\mathrm{U}=0, \mathrm{P}=0,006$, рис. 3$)$.

Из всех изученных самцов только $3 P$. ridibundus и 9 P. esculentus имели в семенниках достаточное для анализа количество мейотических делений (больше 7 качественных пластинок). В семенниках 7 из 9 гибридов вообе не удалось обнаружить сперматоциты I нормальной плоидности. Четыре из таких особей были триплоидами. У остальных диплоидных особей большинство клеток в мейозе имело диплоидный хромосомный набор, который не формировал биваленты нормальной морфологии (рис. 4 В).

При сравнении индивидуальных долей диплоидных митотических пластинок в семенниках диплоидных гибридов и $P$. ridibundus значимых отличий не обнаружено. Анализировали 12 диплоидных гибридов (доля нормальных метафаз варьировала в пределах 9-75\%) и 7 P. ridibundus (11-86\%). Более наглядную картину представленности клеток различной плоидности в семенниках зеленых лягушек дает график распределений усредненных долей клеток различной плоидности у неполовозрелых самцов $P$. ridibundus и двух форм гибридов (рис. 6). 


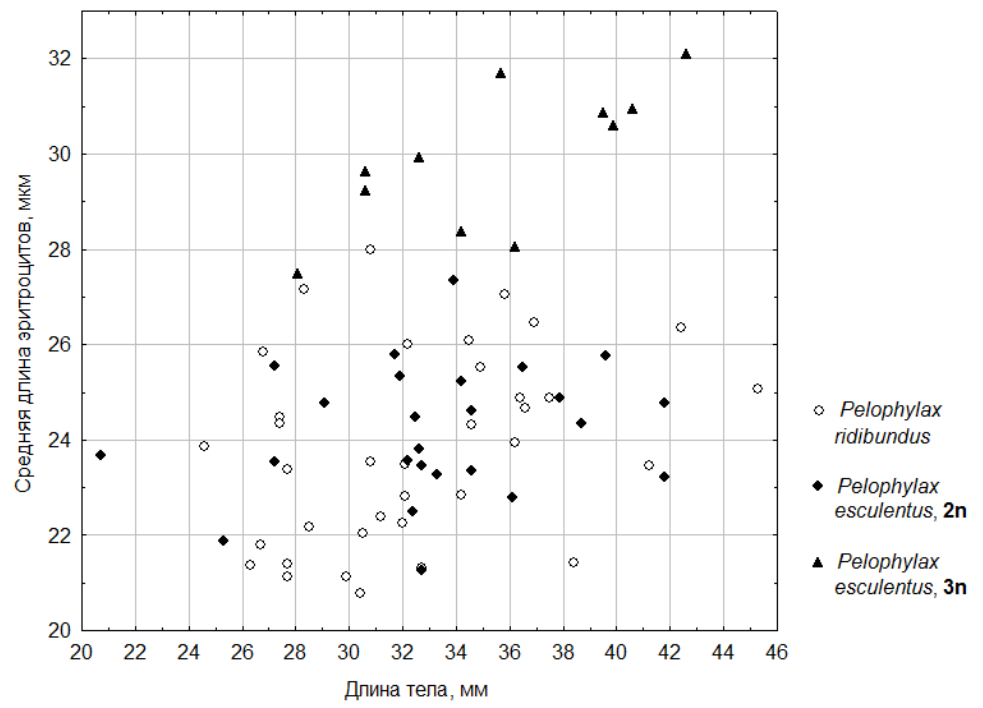

Рис. 1. Отношение средней длины эритроцитов к длине тела у неполовозрелых $P$. ridibundus диплоидных и триплоидных $P$. esculentus

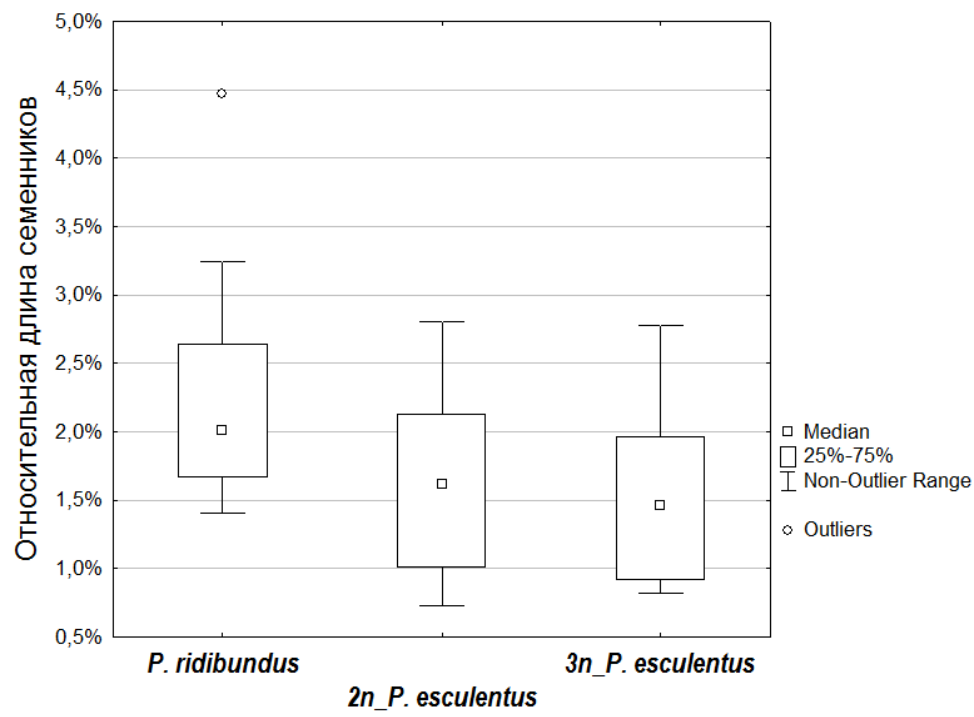

Рис. 2. Средняя относительная длина семенников у неполовозрелых самцов $P$. esculentus complex

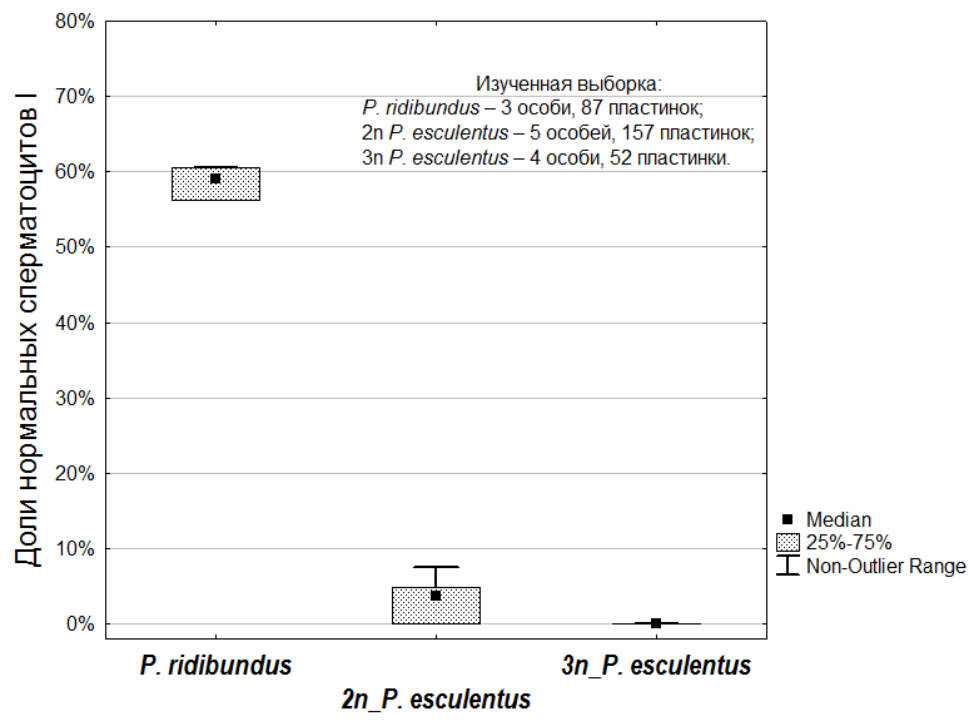

Рис. 3. Доли сперматоцитов I с нормальными кариотипами $(2 \mathrm{n}=13$ бивалентов) в семенниках неполовозрелых самцов $P$. ridibundus и диплоидных и триплоидных $P$. esculentus 
Мы проанализировали 157 сперматоцитов I из семенников пяти диплоидных $P$. esculentus. Большинство клеток имели диплоидный набор хромосом, которые не формировали биваленты нормальной морфологии. Доля таких клеток в среднем для диплоидных гибридов со- ставила 26\%. Мы можем предположить, что такое нарушение образования бивалентов связано со вступлением в мейоз диплоидных клеток, в которых не произошла элиминация одного из родительских геномов и удвоение оставшегося.
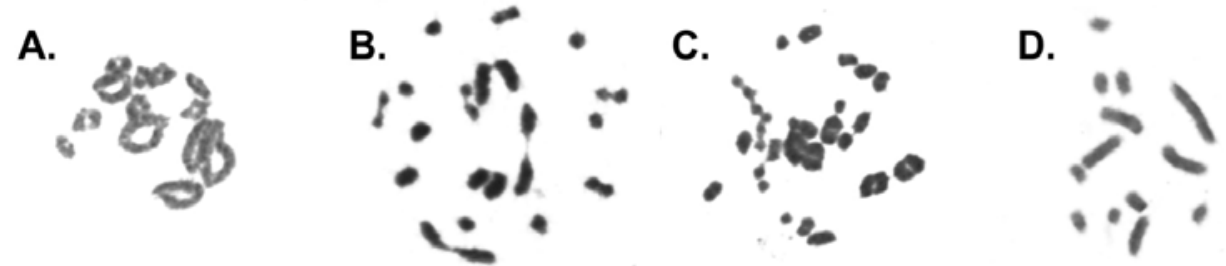

Рис. 4. Сперматоциты I из семенников неполовозрелых зеленых лягушек: А - нормальная 2n пластинка c 13 бивалентами у P. ridibundus; В - аномальная 2n пластинка с 8 бивалентами и 10 унивалентами у диплоидного P. esculentus; C - аномальная 3n пластинка с 11 бивалентами, 13 унивалентами и 1 тетравалентом у триплоидного

$P$. esculentus; D - аномальная гаплоидная пластинка с 13 унивалентами у диплоидного P. esculentus

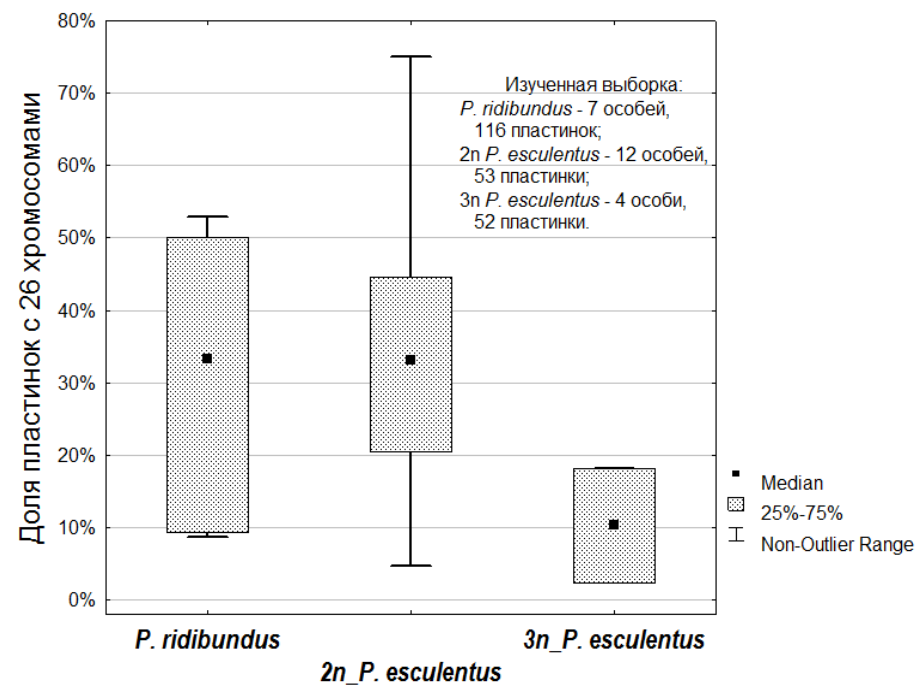

Рис. 5. Доли клеток, находящихся в метафазе митоза, имеющих нормальные диплоидные кариотипы (2n = 26): у триплоидных $P$. esculentus рассматривали только диплоидные клетки

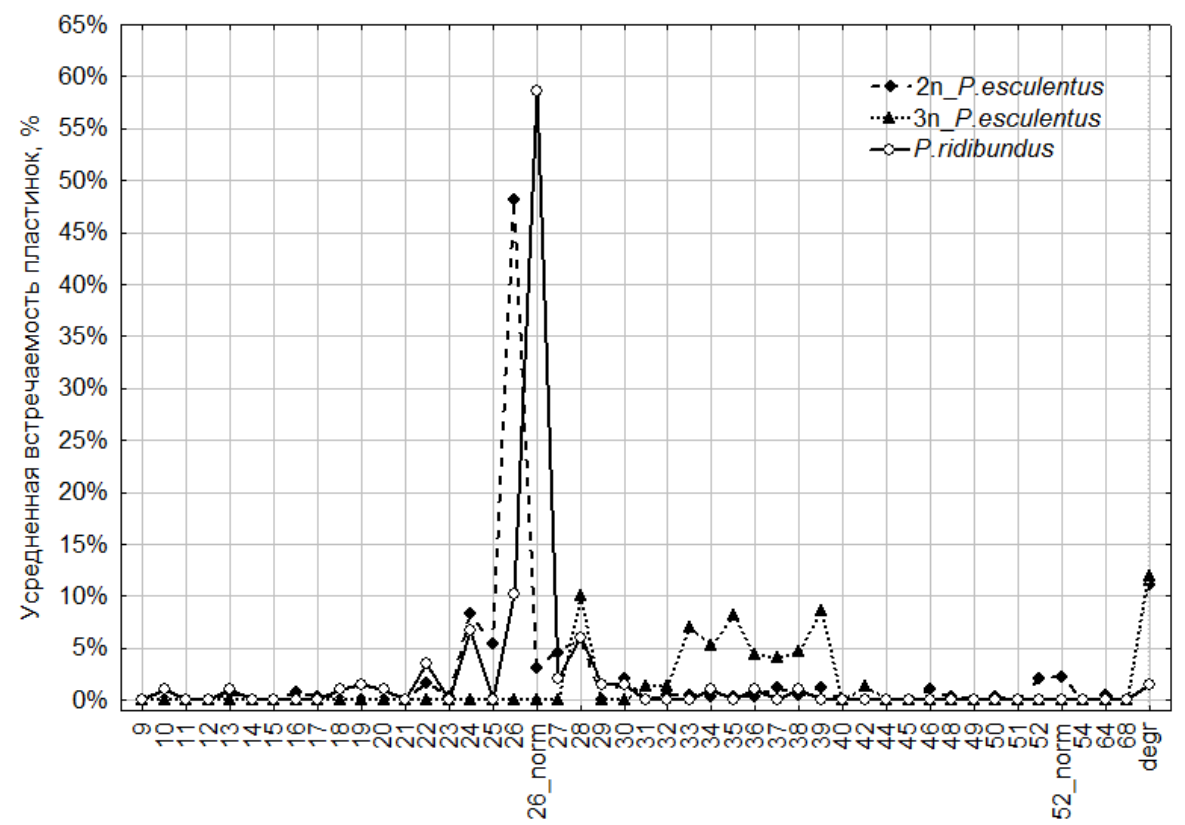

Количество хромосом в профазе мейоза I

Рис. 6. Распределение усредненных частот встречаемости клеток с различным количеством хромосом среди сперматоцитов I у незрелых лягушек: 26_norm соответствует нормальным диплоидным пластинкам, в которых 26 хромосом формируют 13 бивалентов; 52_norm - тетраплоидные пластинки, в которых 52 хромосомы формируют

26 бивалентов; degr - мейотические пластинки с деградирующими структурами, непригодными для подсчета 
В среднем около 4\% сперматоцитов I имели тетраплоидный набор хромосом («52» и «52_norm», рис. 6), но 26 бивалентов нормальной морфологии мы наблюдали только в $2 \%$ мейотических делений. Однако в данном случае усредненный показатель не информативен, так как тетраплоидные сперматоциты I зарегистрированы только у одной особи с достаточным для анализа количеством делений. У этого диплоидного самца тетраплоидные сперматоциты I с 26 бивалентами нормальной морфологии составляли $11 \%$, в то время как у остальных четырех особей этой группы такие сперматоциты вообще не обнаружены.

Как уже говорилось, удвоенный набор хромосом может быть следствием удвоения без элиминации или повторной дупликации. В пользу последнего предположения свидетельствует также факт наличия тетраплоидных (4n) клеток, а также клеток с еще более высоким уровнем плоидности $(5 n, 6 n)$ на стадии метафазы митоза у некоторых особей.
Исследованные неполовозрелые триплоидные самцы вообще не имели нормальных сперматоцитов I с 13 бивалентами (проанализировано 53 пластинки от четырех особей). Около $11 \%$ мейотических делений содержали $39(3 n)$ хромосом в составе бивалентов, мультивалентов и унивалентов. Такие клетки, вероятно, происходят от триплоидных сперматогониев, которые вступили в мейоз без предварительной элиминации одного из родительских геномов.

P. ridibundus демонстрировали более стабильный гаметогенез; 57\% сперматоцитов I несли диплоидный набор хромосом, объединенных в 13 бивалентов (проанализировано 87 пластинок от трех особей). Следует отметить, что у неполовозрелых $P$. ridibundus процент нормальных сперматоцитов I гораздо ниже, чем у половозрелых (Vegerina et al., 2014), что вероятно свидетельствует об отборе против особей с нестабильным клеточным делением. Аналогичным образом проанализированы и митотические деления (рис. 7).

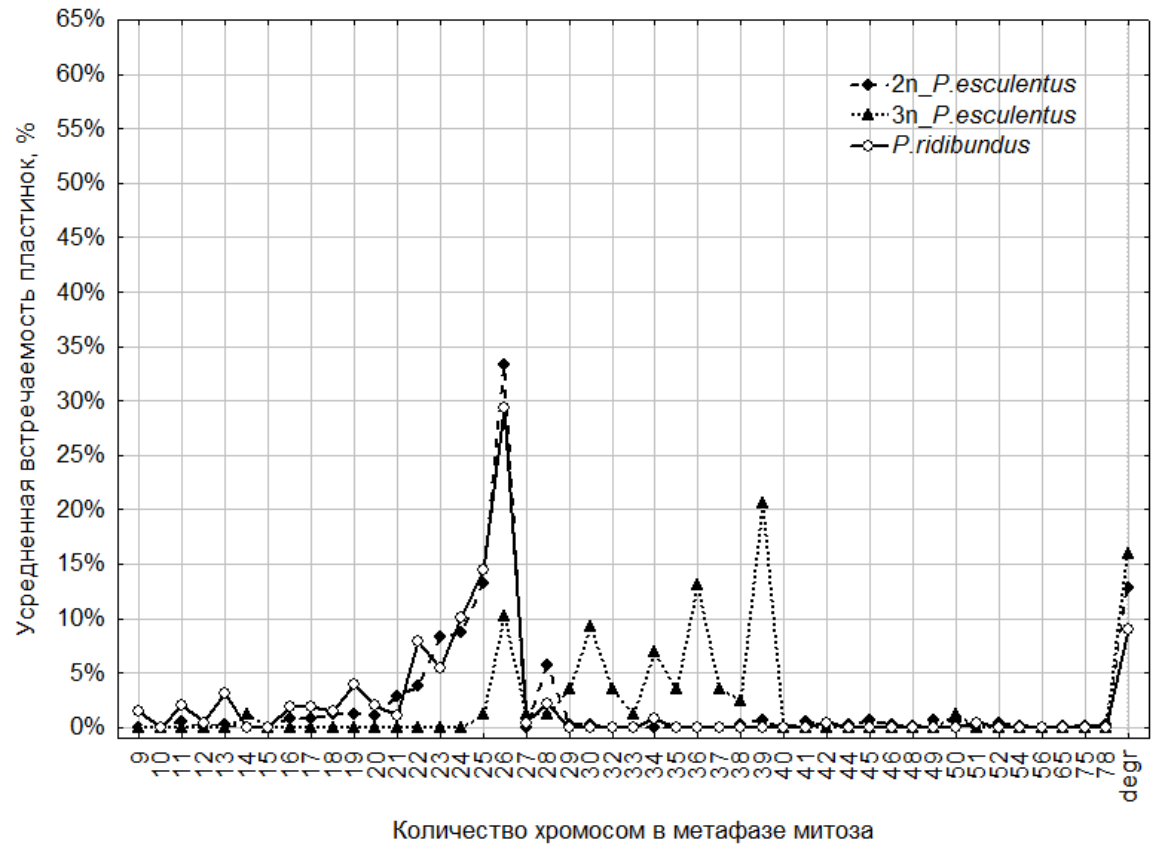

Рис. 7. Распределение частот встречаемости пластинок с различным количеством хромосом среди митотических метафаз у неполовозрелых P. ridibundus, диплоидных и триплоидных P. esculentus:

degr - митотические метафазные пластинки с деградирующими хромосомами, непригодные для подсчета

В статистический анализ вошли данные по 126 митотическим метафазным пластинкам из семенников 7 особей $P$. ridibundus, 297 - из 12 диплоидных P. esculentus и 56 из 4 триплоидных P. esculentus. Сравнительно высокая доля митотически делящихся диплоидных клеток (33\%) у диплоидных гибридов свидетельствует о том, что в семенниках ювенильных гибридов идет активная пролиферация сперматогониев, а отсутствие гаплоидного пика говорит об отсутствии элиминации. Если такие клетки зародышевой линии вступят в мейоз, не пройдя элиминацию, два набора хромосом, принадлежащие разным видам, не смогут нормально сегрегировать и пройти редукционное деление. Вероятно, таким путем возникают сперматоциты, в которых хромосомы не образуют биваленты (рис. 4 В), составляющие наибольший пик у диплоидных гибридов (рис. 6). Что касается митотических делений в семенниках P. ridibundus, то средняя доля дип- лоидных пластинок у них даже несколько ниже, чем у P. esculentus, а само распределение сходно с таковым для диплоидных гибридов. Среди P. ridibundus три наименьших по размеру тела особи демонстрировали нестабильное клеточное деление, и у них доля диплоидных пластинок составляла менее $11 \%$. Остальные $P$. ridibundus имели более $30 \%$ диплоидных пластинок в семенниках и характеризовались более крупными размерами.

Доля диплоидных клеток у триплоидных особей составляла всего $10 \%$, в то время как доля триплоидных метафазных пластинок - 20\%. Наличие диплоидного пика ясно свидетельствует об элиминации одного из родительских геномов (Vinogradov et al., 1991), а большое количество промежуточных анеуплоидных клеток говорит о нестабильности этого процесса. Однако наличие триплоидных сперматоцитов I (рис. 4 С, рис. 6) свидетельствует о том, что предшествующая мейозу элиминация некло- 
нального генома в гаметогенезе триплоидных гибридов может затрагивать не все клеточные линии.

Стоит также отметить большое количество пластинок, несущих деградирующие хромосомы или биваленты («degr», рис. 6 и 7). Разрушение ДНК в этих клетках не связано с повреждением во время приготовления препаратов, так как их количество сильно отличается на препаратах, полученных от разных особей в одинаковых условиях. Посчитать такие структуры зачастую невозможно, однако учет таких пластинок позволяет более адекватно отразить долю тех клеток, которые потенциально дают начало жизнеспособным гаметам.

Проявления отбора на уровне клеточных линий и особей. Более низкая устойчивость сперматогенеза диплоидных, а особенно триплоидных гибридов, по сравнению с таковой представителей родительского вида, является ожидаемым результатом. Удивительнее то, что в гаметогенезе $P$. ridibundus также регистрируется значительное количество аномалий (около 70\% аномальных клеток в митозе и около $40 \%$ - в мейозе). Возможно, это связано с тем, что мы изучали $P$. ridibundus из ГПС, где происходит их активная гибридизация с $P$. esculentus. В таком случае, сперматогенез $P$. ridibundus из чистых популяций должен быть более устойчивым. Авторы планируют проверить это предположение в своих дальнейших исследованиях.

Следующий зарегистрированный нами феномен повышенная устойчивость мейотических делений по сравнению с митотическими. Логично предположить, что не все линии сперматогониев, возникающие в семенниках, переходят к мейозу. На основании этого результата мы предполагаем существование некоего «фильтра», останавливающего развитие клеток с несбалансированным хромосомным набором.

Сравнивая результаты данной и предшествовавшей работ (Vegerina et al., 2014), мы убедились, что сперматогенез зрелых лягушек устойчивее, чем незрелых. Этот феномен может объясняться двумя различными причинами. Во-первых, он может быть связан с удалением из семенников или торможением роста части клеточных линий с аномальными кариотипами. В том случае, если линии сперматогониев с аномальными кариотипами прекращают деления, а клетки с нормальными кариотипами продолжают увеличиваться в числе, общая доля аномалий снижается. Во-вторых, увеличение устойчивости сперматогенеза зрелых лягушек может быть связано с гибелью особей, имевших менее устойчивый сперматогенез. Повышенная вероятность гибели не обязательно должна являться следствием нарушений сперматогенеза; возможно, и нарушения делений, и возрастание вероятности гибели особи могут быть следствием нарушения взаимодействия ее геномов. Как минимум, в случае триплоидов $P$. esculentus можно предположить, что отбор на уровне особей тоже вносит свой вклад в итоговое возрастание устойчивости гаметогенеза. Как указано ранее, зарегистрировано сокращение доли триплоидов в старших возрастных классах, которое мы связываем с отбором (дифференциальной смертностью) индивидов. Одновременно с этим среди зрелых лягушек встречаются триплоиды, способные нормально завершить сперматогенез, а в младших возрастных классах мы таких лягушек не встретили. Нам кажется маловероятным, что у особи, у которой в незрелом состоянии вообще не было клеточных линий с нормальными кариотипами, они смогут появиться в зрелом возрасте. Вероятнее предположить, что особи с особо неустойчивым сперматогенезом гибнут с большей вероятностью, и в результате этого процесса в ГПС возрастает доля триплоидов, способных к успешному сперматогенезу.

Таким образом, мы зарегистрировали последствия отбора на уровне клеточных линий, проявляющиеся в относительно большей устойчивости мейотических делений в семенниках зеленых лягушек по сравнению с митотическими делениями, а также последствия отбора на уровне особей, проявляющиеся в изменении доли триплоидов в разных возрастных классах. Возрастание устойчивости сперматогенеза у зрелых лягушек по сравнению с незрелыми может быть следствием отбора на обоих уровнях.

\section{Выводы}

Метаанализ результатов различных работ, определявших долю триплоидных P. esculentus в выборках зеленых лягушек из поймы р. Северский Донец в окрестностях Биологической станции Харьковского национального университета имени В.Н. Каразина, показал, что эта доля существенно отличается для разных возрастных групп. Ниже всего доля триплоидов среди метаморфов. Среди незрелых лягушек доля триплоидов повышается, видимо, вследствие гибели диплоидных лягушек, появляющихся из-за скрещивания гибридов, передающих клональные геномы одного и того же родительского вида. Среди половозрелых особей доля триплоидов снова несколько снижается, вероятно, в силу более высокой смертности триплоидов в незрелом возрасте.

Незрелые диплоидные лягушки имеют длину эритроцитов менее 28 мкм, триплоидные - более 27 мкм; в диапазоне 27-28 мкм по длине эритроцитов установить плоидность невозможно.

$P$. esculentus (по сравнению с представителями родительского вида $P$. ridibundus той же возрастной группы) в возрасте 2-5 лет имеют тенденцию к задержке развития гонад и значимо большее количество клеток зародышевой линии с аномальными кариотипами.

Спектр кариологических нарушений в гаметогенезе незрелых и взрослых самцов зеленых лягушек в целом сходен, однако зарегистрировано значимое повышение устойчивости гаметогенеза с возрастом, проявляющееся у всех изученных групп:

- в гаметогенезе незрелых $P$. ridibundus регистрируется значительное количество анеуплоидных клеток на стадии митотического (сперматогониального) деления; на стадии мейоза у этих же самцов средняя доля нормальных клеток возрастает до $60 \%$; у взрослых $P$. ridibundus зарегистрировано более 70\% клеток нормальной плоидности, как в митозе, так и в мейозе;

- у диплоидных незрелых P. esculentus большую часть наблюдаемых сперматоцитов составляют клетки с нарушенной сегрегацией, в то время как у взрослых гибридов такие клетки составляли в среднем не больше 15\%; по индивидуальной доле нормальных клеток зрелые особи варьируют в более узких пределах, чем незрелые; 
- у незрелых триплоидных $P$. esculentus не обнаружено нормальных сперматоцитов, в то время как у зрелых триплоидов они зарегистрированы.

Наличие значительного количества аномальных клеточных линий в семенниках зеленых лягушек и повышение устойчивости сперматогенеза с возрастом является свидетельством отбора на уровне клеточных линий и на уровне особей.

\section{Библиографические ссылки}

Berger, L., 1964. Is Rana esculenta lessonae Camerano a distinct species? Ann. Zool. PAN 22(13), 245-261.

Berger, L., 1970. Some characteristics of the crosses within Rana esculenta complex in postlarval development. Ann. Zool. 27, 373-416.

Berger, L., 1971. Viability, sex and morphology of F2 generation within forms of Rana esculenta complex. Zool. Poloniae 21, 349-393.

Berger, L., 2008. European green frogs and their protection. PRODRUK and Ecological Library Foundation.

Berger, L., Günther, R., 1988. Genetic composition and reproduction of water frog populations (Rana kl. esculenta Synklepton) near nature reserve Serrahn, GDR. Arch. Nat Schutz. Landsch. Forsch., Berlin. 28, 265-280.

Biriuk, O., Shabanov, D., Korshunov, O., Borkin, L., Lada, G., Pasynkova, R., Rosanov, Y., Litvinchuk, S., 2016. Gamete production patterns and mating systems in water frogs (hybridogenetic Pelophylax esculentus complex) in NorthWestern Ukraine. Journal of Zoological Systematics and Evolutionary Research (in press).

Bobrova, A.A., Makaryan, R.M., Shejko, V.P., Shabanov, D.A., 2014. Porushennya fertyl'nosti u mizhvydovykh hibrydiv zelenykh zhab iz Sivers'ko-Donets'koho tsentru riznomanittya Pelophylax esculentus complex [Impaired fertility in interspecific hybrids of green frogs from Seversko-Donetskiy center of Pelophylax esculentus complex diversity]. Biologiya ta Valeologiya 16, 7-15 (in Ukrainian).

Bondarieva, A.A., Bibik, J.S., Samilo, S.M., Shabanov, D.A., 2012. Citogeneticheskie osobennosti eritrocitov zelenyh ljagushek iz Seversko-Doneckogo centra raznoobrazija Pelophylax esculentus complex [Erythrocytes cytogenetic characteristics of green frogs from Siversky Donets centre of Pelophylax esculentus complex diversity]. Visnik Harkivs'kogo Nacional'nogo Universitetu imeni V.N. Karazina. Ser. Biologija. 15, 116-123 (in Russian).

Borkin, L.J., Korshunov, A.V., Lada, G.A., Litvinchuk, S.N., Rosanov, J.M., Shabanov, D.A., Zinenko, A.I., 2004. Mass occurrence of polyploid green frogs (Rana esculenta complex) in Eastern Ukraine. Russ. J. Herpetol. 11, 194-213.

Bulger, A.J., Schultz, R.J., 1982. Origin of thermal adaptations in northern versus southern populations of a unisexual hybrid fish. Evolution 36(5), 1041-1050.

Christiansen, D.G., 2009. Gamete types, sex determination and stable equilibria of all-hybrid populations of diploid and triploid edible frogs (Pelophylax esculentus). BMC Evol. Biol. 9, 135.

Christiansen, D.G., Reyer, H-U., 2009. From clonal to sexual hybrids: Genetic recombination via triploids in all-hybrid populations of water frogs. Evolution 63, 1754-1768.

Dedukh, D., Litvinchuk, S., Rosanov, J., Mazepa, G., Saifitdinova, A., Shabanov, D., Krasikova, A., 2015. Optional endoreplication and selective elimination of parental genomes during oogenesis in diploid and triploid hybrid european water frogs. PLoS One 10(4), e0123304.

Dedukh, D., Mazepa, G., Shabanov, D., Rosanov, J., Litvinchuk, S., Saifitdinova, A., Krasikova, A., 2013. Pecedularities of oogenesis in hybridogenetic European water frog complex (Pelophylax esculentus complex). 19th International Chromosome Conference. Dipartimento BiGeA Complesso Belmeloro, Bologna. 128-130.

Guex, G.-D., Hotz, H., Semlitsch, R.D., 2002. Deleterious alleles and differential viability in progeny of natural hemiclonal frogs. Evolution 56(5), 1036-1044.

Günther, R., 1973. Über die verwandtschaftlichen Beziehungen zwischen den europäischen Grünfröschen und den Bastardcharakter von Rana esculenta L. (Anura). Zool. Anz. 190, 250-285.

Günther, R., 1975. Untersuchungen der Meiose bei Mänchen von Rana ridibunda Pall., Rana lessonae Cam. und der Bastardform "Rana esculenta" L. (Anura). Biol. Zent. B1. 94, 277-294.

Kozak, N.A., Gladkova, Y.D., Kulymova, M.D., 2012. Opredelenie doli triploidov sredi Pelophylax esculentus v NPP «Gomol'shanskie lesa» i ego okrestnostjah [Determination of the proportion of triploids among Pelophylax esculentus in NNP "Gomol'shanskie lesa" and the surrounding area]. Biologija: Vid molekuli do biosferi. Mater. VII Mizhnar. konf. mol. naukovciv. FOP Shapovalova T.M., Kharkiv. 261-262 (in Russian).

Manilo, V.V., Radchenko, V.I., 2010. Kariologicheskoe issledovanie Pelophylax ridibundus (Anura, Amphibia) vostochnoj chasti Ukrainy [Karyological study of Pelophylax ridibundus (Anura, Amphibia) of the east part of Ukraine]. Zbirnik Prac' Zoologichnogo Muzeju, Kyiv. 41, 111-121 (in Russian).

Manilo, V.V., Radchenko, V.I., Korschunov, A.V., 2007. Issledovaniye kariotipa s'yedobnoy lyaguschki (Rana kl. esculenta) iz Har'kovskoj oblasti Ukrainy [Comparaive karyological analysis of edible frog (Rana $\mathrm{kl}$ esculenta Linnaeus, 1758) from the Kharkov region of Ukraine]. Naukovy Visnyk Uzhgorods'kogo Universytetu. Ser. Biologia 21, 68-73 (in Russian).

Mezhzherin, S.V., Morozov-Leonov, S.Y., Rostovskaya, O.V., Shabanov, D.A., Sobolenko, L.Y., 2010. The ploidy and genetic structure of hybrid population of water frogs Pelophylax esculentus complex (Amphibia, Ranidae) of Ukraine fauna. Cytology and Genetics 44(4), 212-216.

Ogielska, M., 1995. Oogeneza i róznicowanie si jajnika u hybrydogenetycznegomiesza ca, Rana esculenta L. [Oogenesis and ovary differentiation in the hybridogenetic hybrid, Rana esculenta L.]. Acta Universitatis Wratislaviensis, Prace Zoologiczne 32, 1-42 (in Polish).

Ogielska, M., 2009. Reproduction of amphibians. Science Publishers, Enfield.

Ogielska, M., Bartmaska, J., 1999. Development of testes and differentiation of germ cells in water frogs of the Rana esculenta complex (Amphibia, Anura). Amphibia-Reptilia 20, 251-263.

Plötner, J., 2005. Die westpalaarktischen Wasserfrosche. Bielefeld, Laurenti-Verlag.

Pruvost, N.B.M., Hoffmann, A., Reyer, H.-U., 2013. Gamete production patterns, ploidy, and population genetics reveal evolutionary significant units in hybrid water frogs (Pelophylax esculentus). Ecol. Evol. 3, 2933-2946.

Ragghianti, M., Bucci, S., Marracci, S., Casola, C., Mancino, G., Hotz, H., Guex, G.-D., Plötner, J., Uzzell, T., 2007. Gametogenesis of intergroup hybrids of hemiclonal frogs. Genet. Res. 89, 39-45.

Shabanov, D., Leonov, A., Biriuk, O., Kravchenko, M., Mair, Q., Meleshko, O., Newman, J., Vladymyrova, M., Usova, O., Zholtkevych, G. 2016. Simulation as a tool to identify dynamical typology of Water frog hemiclonal population systems. Acta Biotheor. (in press).

Shabanov, D.A., Litvinchuk, S.N., 2010. Zelenye ljagushki: Zhizn' bez pravil ili osobyj sposob jevoljucii? [Green frogs: Life without rules or special way of evolution?]. Priroda Moscow 3, 29-36 (in Russian).

Shabanov, D.A., Zinenko, A.I., Korshunov, A.V., Kravchenko, M.A., Mazepa, G.A., 2006. Izuchenie populjacionnyh sistem zelenyh ljagushek (Rana esculenta complex) v Har'kovskoj 
oblasti: Istorija, sovremennoe sostojanie i perspektivy [The study of population systems of green frogs (Rana ecsulenta complex) in Kharkiv region: History, modern condition and prospects]. Visnik Harkivs'kogo Nacional'nogo Universitetu im. V.N. Karazina. Serija Biologija 3, 208-220.

Smirina, J.M., 1983. Prizhiznennoe opredelenie vozrasta i retrospektivnaja ocenka razmerov tela seroj zhaby (Bufo bufo) [In vivo determination of age and retrospective evaluation of common toad (Bufo bufo) body sizes]. Zool. Zhurn. 63(3), 437-444.

Suryadna, N.M., 2005. Zeleni zhaby fauny Ukrayiny: Morfolohichna minlyvist', kariolohiya ta osoblyvosti biolohiyi [Green frogs of Ukrainian fauna: Morphological variability, karyology and peculiarities of their biology]. Kyiv (in Ukrainian).

Tunner, H.G., 1974. Die klonale struktur einer wasserfroschpopulation. Z. Zool. Syst. Evolut. - Forsch. 12, 309-314.

Tunner, H.G., 1979. The inheritance of morphology and electrophoretic markers from homotypic crosses of the hybridogenetic Rana esculenta. Mitteilungen aus dem Zoologischen Museum Berlin 55, 89-109.

Tunner, H.G., Heppich-Tunner, S., 1991. Genome exclusion and two strategies of chromosome duplication in oogenesis of a hybrid frog. Naturwissenschaften 78, 32-34.

Usova, E.E., 2010. Skeletohronologicheskoe izuchenie prodolzhitel'nosti zhizni i dinamiki rosta predstavitelej Pelophylax esculentus complex: Registracija otlichij mezhdu bystrorastushhimi i dolgozhivushhimi ljagushkami [The skeletochronological study of the life and growth dynamics of representatives of Pelophylax esculentus complex: Registration of differences between the fast-growing and long-lived frogs]. Bioraznoobrazie i Ustojchivoe Razvitie. Tezisy Mezhdunar. Nauchno-Prakt. Konf. KNC, Simferopol'. 121-124 (in Russian).
Usova, E.E., Kravchenko, M.A., Shabanov, D.A., 2015. Vnutripopuljacionnye ontogeneticheskie strategii u zelenyh ljagushek (Pelophylax esculentus complex) [Intrapopulation developmental strategy of the green frogs (Pelophylax esculentus complex)]. Visnik Harkivs'kogo Nacional'nogo Universitetu imeni V.N. Karazina Serija Biologija 25, 213-227 (in Russian).

Uzzell, T., Günther, R., Berger, L., 1977. Rana ridibunda and Rana esculenta: A leaky hybridogenetic system (Amphibia Salientia). Proceedings of the Academy of Natural Sciences of Philadelphia 128, 147-171.

Vegerina, A.O., Biriuk, O.V., Shabanov, D.A., 2014. Sravnenie ustojchivosti spermatogeneza u gemiklonal'nogo mezhvidovogo gibrida Pelophylax esculentus i roditel'skogo vida Pelophylax ridibundus (Amphibia, Anura) [Comparison of spermatogenesis stability in hemiclonal interspecific hybrid Pelophylax esculentus and parental species Pelophylax ridibundus (Amphibia, Anura)]. Praci Ukrains'kogo Gerpetologichnogo Tovaristva 5, 20-28 (in Russian).

Vegerina, A.O., Meleshko, E.V., Pyrina, I.S., Sapozhnikova, V.A., Biriuk, O.V., 2013. Opredelenie sootnoshenija diploidov i triploidov sredi metamorfov zelenyh ljagushek v Seversko-Doneckom centre raznoobrazija Pelophylax esculentus complex [The determination of the ratio of diploid and triploid green frogs underyearlings from the Pelophylax esculentus complex Seversky Donets diversity center]. Visnik Harkivs'kogo Nacional'nogo Universitetu imeni V.N. Karazina Serija Biologija 18, 107-113 (in Russian).

Vinogradov, A.E., Borkin, L.J., Günther, R., Rosanov, J.M., 1991. Two germ cell lineages with genomes of different species in one and the same animal. Hereditas 114, 245-251.

Надійшла до редколегії 24.03.2016 